\title{
Care-full Community Economies
}

Kelly Dombroski

Stephen Healy

Katharine McKinnon

Chapter forthcoming (2018) in Harcourt, W \& Bauhardt, C. (eds) FEMINIST POLITICAL ECOLOGY AND THE ECONOMICS OF CARE, Routledge.

\section{Introduction}

In this era of human-induced environmental crisis, it is widely recognized that we need to foster better ways to sustain life for people and planet. For us - and other scholars drawing on the Community Economies tradition - better worlds begin in recognising the diverse and interconnected ways human communities secure our livelihoods. Community Economies scholarship is a body of theory that evolved from the writings of geographers J.K. GibsonGraham, which, for more than thirty years, has inspired others (including the three of us) to rethink economy as a space of political possibility. In this chapter we explore some of the common threads between feminist political ecology (FPE) and Community Economies scholarship, highlighting the centrality of care work - women's care work in particular - in the intellectual and empirical heritage of Community Economies Collective (CEC). We argue that an ethic of care has always been central to Community Economies thinking. The question of how to transform our economies in order to allow human and more than human communities to 'survive well together' places care for planetary companions at the heart of our endeavours (Gibson-Graham, Cameron and Healy 2013). In this chapter we focus, however, on the role of care work within Community Economies thinking. For us, 
transforming the economy begins with the feminist project of recognising and revaluing a broader network of care-relationships that are central to all ecologies and economies. We argue that scholarship must begin with making visible the care work involved in transforming the economy for people and planet. Here Joan Tronto's definition of care is helpful. Tronto views care as:

a species activity that includes everything that we do to maintain, continue, and repair our 'world' so that we can live in it as well as possible. That world includes our bodies, our selves, and our environment, all of which we seek to interweave in a complex, life-sustaining web (Fisher and Tronto, 1990: 40, emphasis in original, cited in Tronto 2017, 31)

With this expansive definition we might see care work as already distributed and ubiquitous in maintaining and continuing and repairing our world, but making this more visible is also to show how care work is potentially a distributed and ubiquitous start point in transforming our ecologies and economies. The work of care is required across the wide spectrum of all that is caught up in what Tronto calls the 'life-sustaining web’ of our world. Who it is that does this work is an important consideration - particularly in terms of gender - but so too is the task of thinking about how care work might be shared out and proliferated in an effort to transform the relationships between humans, more-than-humans, and our shared ecological context. In other words, making visible who is doing the care work necessary in transforming our political economies and ecologies is only the first step. Scholars also need to consider what this care work now entails, and how we might - collectively, across gender and other lines of class, sexuality, culture, species - both redistribute and proliferate the work of care for the sake of the human species and the rest of our planetary companions (Dombroski 2017). It is in these ethical negotiations around everyday care practices and care concerns that community economies of care emerge. In this chapter, we have set ourselves the task of detailing a care-full approach to community economies. We believe a sense of the who, what, and how of care is already present in the work of CEC scholars and seek to articulate this 
scholarship and bring it into dialogue with FPE in a way that clarifies our shared concerns. We start with who by exploring a topic that might be closest to home, the gendered care work of intimate infant care. But even here we see that the 'who' caring is a lot more complicated than what it might first appear to be. We extend this further with what, by exploring a geography of the commons as a way of understanding the breadth of what we care for: those things, processes, knowledges, ecosystems and properties that we can (only) share in common. Finally we look at how we do care work, specifically the role that scholarship can play in both acknowledging and revaluing care work in the context of beginning to transform ecologies and economies.

\section{Common threads: CEC and FPE}

The work of the Community Economies Collective and feminist political ecologists have parallel intellectual traditions that are particularly evident through the work of feminist political ecologist, Dianne Rocheleau, and the founding authorial persona of Community Economies, J.K. Gibson-Graham. Our reading of these authors and their associated fields reveals similarities in the shifts taken from feminist strategies which focus primarily on women to those that looked more broadly drew to pay attention to all kinds of marginalized others. We see these kinds of feminist strategies informing a commitment to scholarly care work across the two traditions.

Where political ecology focuses on the interrelationships between social, political and economic factors in shaping environmental change, feminist political ecology is widely understood as placing gender at the centre of the analysis. This is particularly the case in relation to understanding how decision-making practices and socio-political forces influence environmental laws and issues, as well as access to and control over resources (Rocheleau, 
Thomas-Slayter and Wangari 1996). Contemporary feminist political ecology is, however, doing much more than just adding gender into the mix. Diane Rocheleau recently reflected on thirty years of feminist political ecology scholarship, recounting her initial insights from feminist Marxism, early 1990s critiques of Western science, and later, postdevelopment and decolonial theory (Rocheleau 2015). Rocheleau signals an important expansion in describing feminist political ecology as an 'ongoing exploration and construction of a network of learners' rather than 'a fixed approach to a single focus on women and gender' (Rocheleau 2015, 57). Her encounters with indigenous cosmologies transformed the way women's lives and care work are understood as core concerns for feminist political ecology. Feminism here (and across the 'third wave') focused increasingly on the differences among women, and began to attend to all kinds of 'Others' - sexual, cultural, class, ethnic, indigenous and more whose perspectives are essential to a process of engaging with diverse ontologies and decolonising knowledge.

We see a similar transformation taking place in the scholarly trajectories of Julie Graham and Katherine Gibson, central figures in the community economy tradition who came to write under the name J.K. Gibson-Graham. As J.K. Gibson-Graham, Katherine and Julie formulated a theory of diverse economies and have fostered scholarship and activism around community economies. Diverse economies theory asks us to pay attention to the ways in which human livelihoods around the world are secured by a plethora of different modes of economic engagement - many of which are not capitalist. Thus 'the economy' is not made up of capitalism with a smattering of alternative 'other' economic practices - lining up much like gender and sexuality into a binary. Instead, what we have is a diverse (or 'queered', nonbinary) economy, where diverse capitalisms co-exist and rely upon various forms of market and non-market transactions, multiple forms of labour and remuneration, and complex arrays 
of systems for owning and managing property (Cameron and Gibson-Graham 2003). Recognising the already-existing diversity of our economies is a foundational step in fostering what Gibson-Graham termed 'community economies': that is, the particular combinations of work, exchange, production, distribution, investment and ownership that help our communities to survive well (rather than just survive) (Gibson-Graham et al. 2013, Gibson-Graham 2011).

Gibson-Graham (1996, 2006) have described in several places their movement from a realist, empiricist strain of research and anti-capitalist politics to a feminist inflected politics of economic difference and economic possibility. Their work took insights from queer theory, post-structural theory and psychoanalysis to theorise diverse economies based in a recognition of and appreciation for the existence of the many different and varied modes of economic engagement, what we might also call a politics of difference. These insights were later followed by a sustained engagement with actor network and vital materialist theories, theorisations of the commons, as well as insights from ecological humanities and decolonial theory. Each of these have had a deep impact on a politics of economic difference in a now expanding network of theorists who share a similar orientation, in particular the Community Economies Research Network.

Given Gibson-Graham's transformative encounters with theories less obviously feminist, some might wonder where women might be in all of this (see e.g. Bauhardt 2014). For us it is instructive that women's lives are a foundation, or perhaps the starting-point for an enactment of a politics of difference in much of Gibson-Graham's work, and frequently the illustrative examples. In the End of Capitalism it was the domestic lives of Sue and Bill that were used to illustrate the idea that the same people could be party to multiple class processes outside and 
inside the household. In Postcapitalist Politics the diverse economy of childcare is used to explain the diverse organisational forms, labour practices, and market exchanges that compose an economy. Sue and Bill return again in Take Back the Economy to help the reader understand that moving through daily life means encountering diverse forms of private, public, and common property. Each of these examples serve to illustrate the ethical dilemmas and political possibilities in daily life and in our interactions with others. Like feminist political ecology, Community Economies scholarship both recognises and revalues the centrality of women's care work in our economies and ecologies and scholarship. Recognising the significance of these contributions has provided a starting point for recognizing and valuing the contributions of many diverse Others in securing livelihoods and well-being. Ultimately the recognition of diversity provides the starting point for a hopeful politics of transformation.

\section{Who cares?}

Like feminist political ecology, Community Economies scholarship seeks to make explicit who is doing the caring work that societies, economies, human and even more-than-human life depends on. The gendered nature of much of this care work is crucial, and at the same time, Community Economies scholarship is arguing that the explicit acknowledgment of a broader understanding of 'who cares' is also important. CEC scholar Oona Morrow and I (Kelly), for example, argue that while everyday practices of provisioning and care work of (mostly) women in the US and China can reproduce capitalist social relations, they also hold the possibility for altering, undermining and undoing those relations in both contexts (Morrow and Dombroski 2015). Likewise, CEC scholar Gradon Diprose's work on timebanking in Aotearoa New Zealand draws explicitly on a feminist ethic of care to analyse 
the exchanges of care labour by (mostly) women in a timebank with an eye to fostering radical equality (Diprose 2017).

In a care-full community economy, we aim to take the labour and know-how of women, who have done the majority of care work in human societies, and think about how it might be multiplied and shared by an increasing array of actors and an expanded understanding of who it is that cares. The gendered nature of care can thus become a starting point for different sorts of global norms. In paying attention to forms of women's labour that exist outside strictly capitalist structures, it is possible to see how this women's work is both ubiquitous and full of 'postcapitalist' possibility. The post in postcapitalist signals not an 'after' capitalism but already the presence of a 'more' than capitalist that in turn has implications for our desires, and renewed possibilities for collective actions that produce something other than capitalism. We think of women's lives as therefore able to show possibility for a different sort of world built on a feminist ethic of care, a care-full community economy. What can be brought to this then, is a politics of increasing and redistributing caring work, not of shutting down or avoiding care work. Indeed, this key point is the focus of much of our own collaborative work and emerging research projects in maternity and other forms of care (Dombroski, McKinnon and Healy 2016, Dombroski et. al. 2017). This includes redistributing intuitive and obligatory care work to more men (Dombroski 2017) but also using vibrant materialist thinking to extend the 'who' that cares beyond the human (Puig de la Bellacasa 2017).

For us, identifying who it is that cares must take into account the complex and interconnected nature of what it takes to care, which, as Tronto states, must incorporate "our bodies, our selves, and our environment” (Tronto 1993, 103). Community Economies scholarship 
recognises that the work of care is being done by diverse gatherings, not only of people but of many other elements that assemble to enable care work to be undertaken. ${ }^{\text {i }}$ These additional elements include technology and infrastructure, place and territory, bodies and cultures that inflect the doings of women and men. What this means is that we need a broader concept of the 'who' of caring, that takes us beyond gender relations towards an understanding that care work requires the conjoined actions of collectives, the living and non-living things that assemble in order to enable (and sometimes disable) care.

Gerda Roelvink (2016) investigates the collective gathered around the World Social Forum (WSF). Through the WSF, different forms of social change are produced that build on feminist and radical principles, performing care for the multiple economic possibilities latent in the social movements gathered. For Roelvink, one of the central features of the collective is its hybridity. The hybridity of this collective action

includes all that made the WSF possible (such as technologies required for dialogue, tents, and food markets), participants of the WSF and the collectives they represent and more. Taking this point further, the hybrid collective ... reaches out to touch a broader assemblage, including debates in the research fields of social movements studies, actor network theory, neuroscience and pedagogy, and the academic infrastructure through which this knowledge travels (Roelvink 2016, 106).

Roelvink reveals how the WSF hybrid collective pushed her to drop a critical stance that sought always to 'reveal' how social movements were 'really' being co-opted by neoliberalism. In learning to be affected by - and care about - the work of the hybrid collective of which she was now a part, Roelvink began to revise her role as critic. Instead she began to see herself as highlighting and proliferating the alternative economic experimentation already under way. The force of the hybrid care collective "lies in the act of participation and the arousal of hope for new worlds... [and] the experience of learning to be affected in collectives and thereby contributing to the differentiation and proliferation of [...] possibilities for action” (Roelvink, 2016). 
Understanding this array of actors as part of hybrid human-nonhuman collectives pushes third wave feminism into more-than-human territory (Gibson-Graham and Roelvink 2009, GibsonGraham 2011), perhaps even into a fourth wave (Munro 2013). This engagement with human-nonhuman collectives is picked up in my (Kelly's) work around the informal/domestic environmental activism enacted through the collective work of the online forum Oznappyfree. On this forum, users discuss their experiments with a nappy-free form of infant hygiene known as elimination communication. In my analysis, I invoke a hybrid collective where care work is enabled not just by the human actors involved in care work (mothers, fathers, grandparents, infants), but also the material elements engaged (potties, nappies, water and so on). Through the Oznappyfree forum mothers and others use the internet to experiment with and share knowledge about how to 'read' or 'hear' their infants' preverbal communications about impending urination or defecation. These communications produce different assemblages of potties, nappies, water, microbes that are less resource intensive than common Australian assemblages based on using disposable nappies, closer to those used by low and middle income families in China (Dombroski 2015). The human and nonhuman actors that assemble around practices of elimination communication form this hybrid collective, through which the work of care, activism and experimentation is distributed. Both the Chinese and Australian families involved in my study drew my attention to how their everyday, often home-based, practices of care and activism could make a broader contribution. For example, contributions were made by habituating themselves and their children into less-environmentally problematic hygiene norms, through developing attunement and empathy through embodied practice that spreads beyond the home, and through making more possible for more others previously taboo hygiene practices, among other things (see Dombroski 2016). 
From one point of view the membership of Oznappyfree could be considered to just be individual actors in their homes. Via the online forum, however, a collective formed around a set of important environmental and social concerns. Thus the 'who' that acts was no longer a set of individual subjects, but a hybrid activist collective, formed through the assemblage of human and more-than-human actors. The Oznappyfree forum offers a contrast to critical feminist readings focused on how women's environmental work constitutes yet another labour performed in an individualist, neoliberalised context. Instead, narratives of homebased activism on the forum allow us to see the work women do in the home as part of broader, hybrid collective of environmental and political action.

In the context of a care-full community economy, it is important that we identify which of the diverse 'whos' of caring are collective, so we might see and respond not only processes of individualisation of care work brought about by capitalist economic structures, but also see and proliferate collectivisation in care work. In a care-full community the 'who' that cares is a hybrid collective, and we might come to value the diverse actors involved (humannonhuman) and diverse sites and modes of engagement (across global-domestic spheres, with different forms of direct action and everyday politics), helping us recognise the diversity of identities and interrelationships in action at the heart of care-full work. ${ }^{\text {ii }}$

\section{What do we care for?}

If the hybrid collective is the 'who' that is at work caring in the context of community economies, then what is being cared for? For us, the concept that best captures what is being cared for is that of 'the commons'. For example, what members of the Oznappyfree collective are caring for can be understood as a commons. Members of the collective are, of course, 
caring for their infant-members. But their infant hygiene practices are also a way of caring for ecologies by reducing the flow of household waste, benefiting human and more-than-human communities in the process. Further, as the collective freely shares alternative baby hygiene techniques with a broader public via the webgroup, the capacity for collective actions expands beyond the collective itself. In our view, Oznappyfree's care work around the waste stream, infant and parent attachment and communication, and the sharing of this knowledge illustrate a postcapitalist politics of commoning.

For many the term commons is associated with pre-capitalist communities that were often sustained by access to commons, in the form of forests, fields and fisheries to which commoners had rights of access and use. Like feminist political ecologist Christa Wichterich (2015), Gibson-Graham, Cameron and I (Stephen) (2013) emphasize the important relationship between the commons of the past and commoning in the present. Contemporary commons are physical resources, knowledges, and cultural practices that are distinct from private property in that access, use, benefit but also responsibility and care are widely distributed (Barbagallo and Federici, 2012, and Linebaugh, 2008, following Bollier, 2002). This focus on the sociality that defines commons draws our attention away from "the commons" and towards a process of commoning.

We define commoning as a set of social processes and protocols that establish the rules of access, use, and benefit in relation to commons - whether those commons are, for example, areas of oceans, the internet, or a public library (see figure 1, The Commons Identikit, where the shaded areas indicate ). In addition, commoning processes set rules over who is responsible for the care of that which is commoned (Barbagallo and Federici 2012, Linebaugh 2008, Bollier 2002). 
Figure 1: The Commons Identikit

\begin{tabular}{|c|c|c|c|c|c|c|}
\hline \multirow{3}{*}{$\begin{array}{l}\text { Commoning } \\
\text { enclosed } \\
\text { property }\end{array}$} & \multirow{2}{*}{ Access } & & & & & \\
\hline & & Use & Benefit & Care & Responsibility & Ownership \\
\hline & Narrow & $\begin{array}{c}\text { Restricted by } \\
\text { owner }\end{array}$ & Private & $\begin{array}{c}\text { Performed by } \\
\text { owner or } \\
\text { employee }\end{array}$ & $\begin{array}{c}\text { Assumed by } \\
\text { owner }\end{array}$ & $\begin{array}{c}\text { Private } \\
\text { individual } \\
\text { Private } \\
\text { collective } \\
\text { State }\end{array}$ \\
\hline $\begin{array}{l}\text { Creating } \\
\text { new } \\
\text { commons }\end{array}$ & $\begin{array}{l}\text { Shared and } \\
\text { wide }\end{array}$ & $\begin{array}{l}\text { Negotiated by a } \\
\text { community }\end{array}$ & $\begin{array}{c}\text { Widely } \\
\text { distributed to } \\
\text { community and } \\
\text { beyond }\end{array}$ & $\begin{array}{l}\text { Performed by } \\
\text { community } \\
\text { members }\end{array}$ & $\begin{array}{l}\text { Assumed by } \\
\text { community }\end{array}$ & $\begin{array}{c}\text { Private } \\
\text { individual } \\
\text { Private } \\
\text { collective } \\
\text { State } \\
\text { Open access }\end{array}$ \\
\hline $\begin{array}{l}\text { Commoning } \\
\text { unmanaged } \\
\text { open-access } \\
\text { resources }\end{array}$ & Unrestricted & $\begin{array}{c}\text { Open and } \\
\text { unregulated }\end{array}$ & Finders keepers & None & None & $\begin{array}{c}\text { Open access } \\
\text { State }\end{array}$ \\
\hline
\end{tabular}

The shaded area indicates the criteria for identifying a common. 'Commoning' refers to the process of bringing either private or open-access property and resources into common access, use, benefit, care and responsibility.

Source: Gibson-Graham, J. K., J. Cameron \& S. Healy. 2013. Take Back the Economy: An ethical guide for transforming our communities. Minneapolis: University of Minnesota Press. Image used under Creative Commons.

Focusing attention on the process of commoning opens up our understanding of what might be held in common: open-access resources like the atmosphere and oceans may be commoned through the establishment of the rules of use and care; the digital-knowledge commons may be defended from forces of neglect or enclosure; and even private property may be partially commoned in the interest of community and ecological wellbeing. Many scholars in the Community Economies Collective and beyond are, however, identifying common resources such as fisheries (St. Martin and Hall-Arber 2008), non-timber forest products (Emery and Barron 2010), and healthy soils (Roelvink 2016) as commons both used, and cared for, by human communities. While commons and their commoning 
communities are easier to spot when they are a natural resource, commoning and commons can also be seen elsewhere when we know what to look for.

One such example of commoning in the city occurs in Fairmount Park, Philadelphia, one of the largest urban parks in the US. From its initial establishment in 1851, there was an ongoing struggle over how the park-space was to be accessed, used, and to whose benefit, and who would exercise care and responsibility for it (Gabriel 2016, refer also to Figure 1., Gabriel 2011). Urban planners, at the time, understood parks as recreational spaces that helped the turn of the century industrial city to function effectively, by providing a defined place for leisure away from industry. The photographic record developed during this same period of time re-enforced an image of the park-as-recreation by excluding other, contending uses of park space. In fact, the park was also a site of self-provisioning: fruit and nut gathering, hunting, commercial ice harvest in winter, firewood gathering, and even milling for timber. While these productive uses of park-space were later discouraged, the fruit and nut trees were never removed from the park and in the present-day, many of Philadelphia's newest residents still gather resources from the park.

Like many cities in the minority world, Philadelphia has since experienced wholesale industrial decline and abandonment. Some of the empty space left behind has been filled with commons and their communities. Community Economies scholars have examined a number of different forms of emerging city-based commoning practices in a variety of places, including Philadelphia. Commoning practices include the creation of community gardens (Borowiak, 2015, Morrow, 2014, Sharp et al., 2015, Cameron et al., 2011), maker spaces (Loh and Shear, 2015), commoned forms of housing (Crabtree, 2006, Huron, 2015), and community-based approaches to low carbon energy systems (Cameron and Hicks, 2014). 
Such collective efforts distribute the burden and benefits of remaking city-space through practices of commoning.

What can be learned from examples of commoning in the city is that through collective action we have the capacity to care on a scale that exceeds the local. In a community economy of care, hybrid collectives gather to care for commons that, in turn, sustain the collective. A commoning of the atmosphere is one such collective act of care to 'sustain the collective'. Commoning the atmosphere as a response to climate change seems like an almost impossible task. Yet even here it is possible to look back at recent history to see a community of carers assembling that may prove commensurate with the task.

Cameron, Gibson-Graham and I (Stephen) describe an example of intergenerational atmospheric commoning that gives us reason to hope. In industrial communities such as Newcastle, the coal and steel industry choked the air with a thick smog of particulates. As early as the 1930s, communities comprised of both working class and management began to measure particulate levels in their communities, pressuring local councils to be early adopters of regulatory frameworks that aimed to improve local air quality. These frameworks prefigured national clean air legislation passed in Australia and the UK in the 1950s and 60s followed by the US in the 1970s. A still larger hybrid collective was required to first discover and then counter the threat posed by ozone depleting chemical such as chlorofluorocarbons. While researchers in Australia and elsewhere had begun sounding the alarm about the integrity of upper atmospheric ozone depletion, it was not until spectral satellite data actually made visible the extent of the damage that the Australian public pressured the government to take decisive action. The Australian government played a key role of brokering between minority and majority worlds, including establishing a differential timetable and terms of 
financial support for the Montreal Protocol passed in 1987. While this effort at an internationalisation of care for the upper-ozone commons was crucially important, other efforts were equally so: in the 1980s, the union of plumbers and pipe fitters in Australia refused en masse to install any fire suppressant system that contained ozone destroying chemicals - which in turn ultimately pressured real estate developers to then pressure manufacturers for an alternative.

The story we tell here is of a range of social actors coming together in an ongoing and evolving assemblage in order to enact change. Responding to the perceived threat to their own health and the larger environment, different groups found a reason to care enough to act, to enact a care work of atmospheric repair. The commons in question only came into view as an object through scientific inquiry; the commoning-community - in this case a hybrid collective - only came into being in response to the threat the inquiry revealed. The collective that came into being acted on concerns that stretched beyond any one interest group. Furthermore, the work of atmospheric caring will stretch well beyond a single generation. Ozone destroying CFCs were first synthesized in 1911 and the ozone hole is unlikely to be completely repaired until 2085-meaning the practice of atmospheric care stretches over seven generations. Both the scale and concerted intergenerational effort required to respond to the challenge of climate change will span our lifetime and those that will come after us.

In tracing this trajectory, we see a repeating pattern where new understandings of the nature and extent of the problem can elicit a response: a shared concern develops, a call to action is heard, and a response envisioned and enacted through the work of care. Caring for the atmospheric commons in response to climate change will require the assembling of a far greater hybrid collective still, one that will be undaunted by setbacks along the way. While 
some government actions (such as carbon pricing) have suffered reversal in Australia in recent years, other changes (such as the profusion of photovoltaic technologies combined with home battery energy storage) have remade energy markets. Consumers of these technologies have organised into a political constituency of solar citizens that may make this emergent distributed energy technology harder to dislodge or undermine politically, while simultaneously new forms of financing for their installation on commercial and residential properties may allow them to spread further. Photovoltaic energy generation, new forms of storage, new forms of financing, sharing these innovations, emergent civic conscience, can become a powerful hybrid collective that allows for people in Australia and elsewhere to common the atmosphere by means of caring for it.

While the challenges of addressing issues such as the anthropogenic origins of climate change are significant, what this example shows us is that it is possible to bring into being new collectives who undertake commoning around broadly defied shared interests. Even if some are motivated to participate in this emergent collective for purely "selfish" reasoning, such people are part of a larger and ongoing practice of atmospheric commoning, performing care work. Awareness of the relationship between complex-assemblage actors and the commons they constitute and care for may help innovative practices to spread farther and more quickly than they otherwise might. In a care-full community economy, as commons are identified that require care, they call into being the collective-community that both makes use of and cares for them - we can see this trajectory through responses to commoning the ozone layer, and we see the beginnings of a parallel trajectory emerging to common the atmosphere more generally.

How do we care? 
While care may happen through collective action that emerges consciously, or unconsciously, in this chapter we wish to pay attention to how we, as academics, researchers and writers, may care. For Community Economies scholars, commoning and contributing as part of collectives that care are not just practices that happens outside the academy, driven by those whom might be counted as research participants. As for FPE, feminist research methods highlight the political dimension of scholarly research, reminding us that our everyday practices as scholars researching and teaching in the academy also have performative effects. The performativity of research has been a central feature of diverse economies critique, ever since Gibson-Graham argued that repeated invocation of the hegemonic power of global capitalism serves only to reinforce and reinscribe that power (1996). Constantly seeking to line up analysis in certain patterns works to perform and re-perform the very structures we might wish to oppose and disrupt (Roelvink, 2016). The methods researchers choose to describe reality also work to amplify the particular reality described (Law 2004, Roelvink 2016, Werner 2015). Thus, care-full work in the academy comes with selection of methods that, for example, distributes control to participants and 'consumers' in knowledge production. Community economies of care can be supported by researchers working to connect together small scale projects in community building and community empowerment in to the bigger pictures that participants are envisioning (Werner, 2015). This provides discursive space for these experimental projects to be amplified beyond the local.

Reflecting on their work with community gardens in Newcastle, Australia and alternative food economies in the Philippines, Community Economies researchers Jenny Cameron, Katherine Gibson and Ann Hill explore "the role that research might play in fostering and caring for new community food economies” (Cameron, Gibson and Hill 2014, 4). They focus on three techniques of hybrid collectives: gathering, re-assembling, and translating. In 
Newcastle, the Newcastle Community Garden Project engaged members of community gardens from across the city join together in a bus trip to visit each other's gardens, and bring together the different knowledge and know-how that emerged from this hybrid collective of gardeners, plants, compost heaps, garden beds and more. Cameron and her collaborators approached the project with a care to strengthening community food economies, adopting

a stance of openness so we are ready for possibilities to arise, especially those that realise our research intentions and start to make fragile, imaginative constructions of the new more durable (Cameron et al. 2014, 13).

'Reassembling' is performed, in this case, by utilising the fruitful exchanges that emerged during the garden bus trip as the foundations for co-theorisation with research participants. The process involved literally re-assembling and amplifying the reflections and utterances from the bus trip, providing voice-over narration in a film about the gardens. This recrafting of 'raw data' is a familiar process for a researcher, but involving the gardeners themselves in the process provided an opportunity to amplify the performative potential of knowledgemaking. This was an 'important means of reframing and clarifying' (Cameron et al. 2014, 16) what the garden project was doing, connecting gardeners to the broader significance of their efforts. They use the term 'translation' to describe the process through which outcomes are relayed through indeterminate networks and connections, because they are 'translated' for use in other contexts and places beyond the participants who contributed to original gatherings and re-assemblages. The 'translated' academic papers, popular films and other forms of communication can be taken up by other groups in ways that are unpredictable.

These three methodological interventions - gathering, reassembling and translating - are deliberate strategies to undertake an action research approach that seeks to "participate in bringing [economic food] futures into being” (Cameron et al. 2014, 22). But this is participating without controlling, enacting an ethical decision to do research in the spirit of 
openness, practicing care for (earth) others through co-creation of outcomes that have a life of their own, spreading in ways which, the authors hope, "might increase the chances of community food economies becoming more visible, more interconnected and thus more robust” (Cameron et al. 2014, 24). In describing the messy and unpredictable processes involved in hybrid research collective methods, Cameron, Gibson and Hill are describing a way in which researchers find ways to care for others. In this case, care involves establishing caring relationships with research participants, in part through a co-production and cotheorisation process that accords participants respect and control. Care is also entailed by the intention to give outcomes a life of their own, encouraging them to be translated outwards.

As Tronto (2017) states, the identification of how we care also can involve translating between context-specific understandings of how to care. These dynamics came to the fore in a project focused on gender equity and economic empowerment in the Pacific, which I (Katharine) worked on (McKinnon et al. 2016). In this project the research team was tasked with working with communities to develop community based indicators for gender equity. The tools already available to track the potential impacts of proposed Pacific free trade agreements on household economies are unable to account for the range of livelihood strategies that many Pacific and Melanesian communities rely on. Furthermore, existing gender equity indicators are based on normative visions of gender equity based in Western European conceptualisations of individual rights (McKinnon et al. 2016). The Community Economies scholars involved in this project wanted to avoid simply translating existing conceptualisations for the local context. Instead we sought to facilitate the emergence of place-based conceptualisations of gender equity. These could then inform a Pacific-wide toolkit for tracking gender equity and economic developments in a way that was meaningful 
in the Pacific context, and could contribute to a version of 'women's economic empowerment' on their own terms.

In partnership with the International Women’s Development Agency and local NGOs in Fiji and the Solomon Islands, Katherine Gibson, Michelle Carnegie, and I (Katharine) ran participatory workshops to explore gendered economies with community members (Carnegie et al. 2012). The research explored the role of informal and social economic activities in people’s livelihoods. Informal market exchange, unpaid labour in the household, subsistence production, volunteer work, and gift exchange across wider family and community networks were found to form the core of people's livelihoods. Explorations of local diverse economies also uncovered a gendered economy, in which the roles and responsibilities of women and men were complementary. While participants were concerned about instances of inequity, most advocated a vision of complementarity in gendered work, and the expression of aspirations for gender equity tended to not be about sameness, but about having the different contributions of women and men equally respected and valued.

Based on the understandings of gender equality and the gendered economy developed through community engagements, we developed a set of indicators that could be used to track important changes to livelihood practices and gender (Carnegie et al., 2012). An important component of this is recording and keeping track of the ways that people care for one another, and the equitability of care work provided by women and men. Unpaid care for children and elders was a part of this, so too was the care given to community when men volunteered to build and maintain church infrastructure, or women laboured to make flower displays for weekly church services. Turning insights of the interdependent economies of women and men into measurable indicators, this work provides a way to begin to make 
visible and to value the diverse livelihoods of Pacific communities, and the networks of interrelationships that provide for individual, household and community wellbeing. We might see this as part of the work of both sustaining social and knowledge commons, the circuits of care that constitute and sustain the collective. Care-full community economy scholarship, in addition to recognising the hybrid collectives who care and the commons that we care for, deploys the tools of social research to contribute to building community economies of care. We agree with feminist political ecologists that is critical to establish "the connection between exploitation of women's labour the abuse of planetary resources" as a precondition for caring for those people and things neglected and abused (Mellor 2005, 123 quoted in Brauhardt 2014, 61). But this is only a beginning. This care-full critical scholarship may allow us to also enlarge the "we" who cares, deepen our shared commitment to the commons that sustain us, and to continuously learn through a process of engaged research.

\section{Conclusion}

In this chapter, we have presented a particular imagining of what constitutes the collective, what constitutes the more-than/other-than/non-human earth others who are cared for in commoning practices, and what practices we can engage to care in, and through, our research. But economies of care are not just made up of collectives, commons, and earth-others larger than ourselves. The picture is always more complex - for one, collectives are made up of singular human beings, with subjectivities ascribed and claimed in different ways. What they seek to act upon may not be held in common, or may not be recognised as part of a being-incommon (or in fact a desirable inclusion in a commons). Research sometimes has to serve other goals and desires, fulfilling criteria and priorities of funding agencies among them. All of these activities are undertaken by, in, and through, bodies that are positioned differently in place and relations of power, and are often (always) unruly 'leaky' containers for human 
agency (Longhurst 2001). Caring involves, as Puig de la Bellacasa (2011) puts it, 'everyday doings' that are neither straightforward nor coherent: We need to ask 'how to care' in each situation. The who, what and how of a community economy of care are always open to ongoing negotiation and redefinition.

Our discussions in this chapter have focused on questions of who it is that provides care, and for whom, and how we as researchers can contribute to this while remaining open to an ongoing process of negotiation. The work of hybrid collectives and attentiveness to commons is at the core of how we see and practice community economies of care. Throughout, we have begun to articulate what a Community Economies approach to care looks like as we build on foundations provided by second and third wave feminism, as we seek to not just critique but create and proliferate care-full practices.

With the feminist political ecology tradition, Community Economies scholars are concerned for the complex and multiple dynamics through which societies, economies and environments interrelate, and for the gendered nature of all this. Yet, the feminism much Community Economies scholarship is informed by is decidedly third wave - it is about much more than thinking with and through the perspectives of women. Rather it is learning to see and think differently with all the perspectives, experiences and concerns that might be side-lined as 'Other' to the dominant mode.

The 'community' in our community economy of care is understood to include a multiplicity of others with whom being-in-common is negotiated. This includes not just women, and indeed not just the human actors but a diverse range of other-than-human actors. A community economy is now being envisioned as something that incorporates a complex 
ecology in which human livelihoods, planetary well-being, and care for the more-than-human are understood as interconnected and mutually dependent (McKinnon et al. 2016, Dombroski, McKinnon and Healy 2016). The shared work of building community economies involves actively caring for, and recognising the agency of, human and non-human, identifying diverse ways of being from which caring economies can be fostered. It also involves finding ways to make the work we do as researchers and academics productive of the types of community economies we wish to foster. In a community economy of care, an ethical stance of openness to difference and diversity makes appreciative investigation possible, in which alternatives and the unexpected sources of learning are not foreclosed by the imposition of 'strong theory’(Sedgwick 1994, see also Roelvink 2016, Gibson-Graham 2006, Diprose 2016). In a community economy of care, the relationality of livelihoods and economies are foregrounded, allowing us to focus on the ways that practices of economy create opportunities to care for human and non-human others. In a community economy of care, how we conduct ourselves, as citizens and as researchers, provides daily opportunities to perform alternative futures into being where care is more widely distributed.

\section{References}

Barbagallo, C. \& S. Federici (2012) Introduction: Care work on Commons. The Commoner, Winter, http://www.commoner.org.uk/.

Bauhardt, C. (2014) Solutions to the crisis? The Green New Deal, Degrowth, and the Solidarity Economy: Alternatives to the capitalist growth economy from an ecofeminist economics perspective. Ecological Economic, 102, 60-68.

Bollier, D. 2002. Silent theft: the private plunder of our common wealth. New York: Routledge.

Cameron, J. \& J. K. Gibson-Graham (2003) Feminising the economy: metaphors, strategies, politics. Gender, Place and Culture: A Journal of Feminist Geography, 10, 145-157.

Cameron, J., K. Gibson \& A. Hill (2014) Cultivating hybrid collectives: research methods for enacting community food economies in Australia and the Philippines. Local Environment, 19, 118-132.

Carnegie, M., C. Rowland, K. Gibson, K. McKinnon, J. Crawford \& C. Slatter. 2012. Gender and economy in Melanesian communities: A manual of indicators and tools to track 
change. University of Western Sydney, Macquarie University and International Women's Development Agency.

Diprose, G. (2016) Negotiating interdependence and anxiety in community economies. Environment and Planning A, 56, 1411-1427.

--- (2017) Radical equality and labour in a community economy Gender Place and Culture, 24, 834-850.

Dombroski, K. (2015) Multiplying Possibilities: A postdevelopment approach to hygiene and sanitation in Northwest China. Asia Pacific Viewpoint, 56, 321-334.

--- (2016) Hybrid Activist Collectives: Reframing mothers' environmental and caring labour. International Journal of Sociology and Social Policy, 9/10, 629-646.

--- (2017) Learning to be affected: Maternal connection, intuition and 'elimination

communication'. Emotion, Space and Society. DOI: 10.1016/j.emospa.2017.09.004

Dombroski, K., A. F. Watkins, H. Fitt, J. Frater, K. Banwell, K. Mackenzie, L. Mutambo, K. Hawke, F. Persendt, J. Turković, S. Y. Ko \& D. Hart (2017) Journeying from "I" to "we": assembling hybrid caring collectives of geography doctoral scholars. Journal of Geography in Higher Education, 1-14. DOI: 10.1080/03098265.2017.1335295

Dombroski, K., K. McKinnon \& S. Healy (2016) Beyond the birth wars: Diverse assemblages of care. New Zealand Geographer, 72, 230-239.

Emery, M. R. \& E. S. Barron (2010) Using Local Ecological Knowledge to Assess Morel Decline in the U.S. Mid-Atlantic Region. Economic Botany, 64, 205-216.

Gabriel, N. (2011) The work that parks do: towards an urban environmentality. Social \& Cultural Geography, 12, 123-141.

---. 2016. Visualizing Urban Nature in Fairmount Park: Discipline, Economic Diversity, and Photography in Nineteenth-Century Philadelphia. In A Greene Country Towne: Art, Culture, and Ecology in Philadelphia, eds. A. C. Braddock \& L. T. Igoe. Pennsylvania: Penn State University Press.

Gibson-Graham, J. K. 1996. The End of Capitalism (As We Knew It). Minneapolis: University of Minnesota Press.

---. 2006. A Postcapitalist Politics. Minneapolis and London: University of Minnesota Press.

Gibson-Graham, J. K. (2011) A feminist project of belonging for the Anthropocene. Gender, Place \& Culture, 18, 1-21.

Gibson-Graham, J. K. \& G. Roelvink (2009) An Economic Ethics for the Anthropocene. Antipode, 41, 320-346.

Gibson-Graham, J. K., J. Cameron \& S. Healy. 2013. Take Back the Economy: An ethical guide for transforming our communities. Minneapolis: University of Minnesota Press.

Law, J. 2004. After method: mess in social science research. London and New York: Routledge.

Linebaugh, P. 2008. The Magna Carta Manifesto: Liberties and Commons for All. Berkeley: University of California Press.

Longhurst, R. 2001. Bodies: Exploring Fluid Boundaries. London: Routledge.

McKinnon, K., M. Carnegie, K. Gibson \& C. Rowland (2016) Gender equality and economic empowerment in the Solomon Islands and Fiji: a place-based approach. Gender, Place \& Culture, 23, 1376-1391.

Morrow, O. \& K. Dombroski. 2015. Enacting a postcapitalist politics through the sites and practices of life's work. In Precarious Worlds: Contested geographies of social reproduction, eds. K. Meehan \& K. Strauss, 82-98. Athens, GA: University of Georgia Press.

Munro, E. (2013) Feminism: A Fourth Wave? Political Insight, 4, 22-25.

Puig de la Bellacasa, M. (2011) Matters of care in technoscience: Assembling neglected things. Social Studies of Science, 41, 85-106. 
Puig de la Bellacasa, M. 2017. Matters of Care: Speculative ethics in more than human worlds. Minneapolis: University of Minnesota press.

Rocheleau, D. 2015. A situated view of feminist Political ecology from my networks, roots and territories. In Practicing Feminist Political Ecology: Moving Beyond the Green Economy, eds. W. Harcourt \& I. L. Nelson, 29-66. London: Zed Books.

Rocheleau, D., B. Thomas-Slayter \& E. Wangari. 1996. Gender and Environment: A feminist political ecology perspective. In Feminist Political Ecology: Global perspectives and local insights, eds. D. Rocheleau, B. Thomas-Slayter \& E. Wangari, 3-23. New York: Routledge.

Roelvink, G. 2016. Building Dignified Worlds: Geographies of Collective Action. Minneapolis: University of Minnesota Press.

Sedgwick, E. K. 1994. Tendencies. London: Routledge.

St. Martin, K. \& M. Hall-Arber (2008) The missing layer: Geo-technologies, communities, and implications for marine spatial planning. Marine Policy, 32, 779-786.

Tronto, J. 2017. There is an alternative: homines curans and the limits of neoliberalism. International Journal of Care and Caring, 1, 27-43.

Tronto, J. C. 1993. Moral boundaries: A political argument for an ethic of care. Psychology Press.

Werner, K. 2015. Performing economies of care in a New England time bank and Buddhist community. In Making Other Worlds possible, eds. G. Roelvink, K. St Martin \& J. K. Gibson-Graham, 72-97. Minneapolis: University of Minnesota Press.

Wichterich, C. 2015. Contesting green growth, connecting care, commons and enough. In Practicing feminist political ecologies: Moving beyond the green economy, eds. W. Harcourt \& I. Nelson, 67-100. London: Zed Books.

\footnotetext{
' Our use of the term 'assemble' here is deliberate, and we intend it to signal out engagement with actor network theory and materialist perspectives that explore ideas of assemblage (see Law 2004 for example). Space does not allow us to elaborate more deeply.

ii See Dombroski 2016 for further discussion of this politics of the everyday act.
} 